\title{
Entrepreneurial Intention, Entrepreneurial Knowledge and Entrepreneurial Behavior of Female Students in Higher Vocational Colleges: An Interactive perspective
}

\author{
Guan-yitong ZHOU ${ }^{12}$ \\ School of Business/Ph.D. Candidate, \\ 1 Macau University of Science and Technology \\ 2 Guangdong Institute of Science and Technology \\ Macau/Zhuhai, China \\ Email:grania_chou@foxmail.com
}

\author{
Mu-yan RUAN \\ School of Business /Ph.D. Candidate, \\ Macau University of Science and Technology \\ Macau \\ Email:my33mu@hotmail.com
}

\author{
Xiao-yang YANG \\ School of Business/Ph.D. Candidate, \\ Macau University of Science and Technology \\ Macau \\ Email:sscolins@163.com
}

\begin{abstract}
In recent years, colleges have paid more attention to entrepreneurship education. The government in china emphasizes much on the entrepreneurship issues, puts forward many programs and policies of supporting college students' entrepreneurship, and encourages them to start their own business or entrepreneurial activities, but college students are faced with different challenges and risks in their real entrepreneurial activities all the time. At present, there are many researches on the entrepreneur intention of college students. In this research, based on the Theory of Planned Behavior (Ajzen, 1991)[2],we discusses the entrepreneurial behavior of female students in higher vocational colleges, mediating role of creativity and moderating Effect of entrepreneurial knowledge, which are analyzed from the view of gender. The female students in higher vocational colleges are taken as the target of investigation to discuss the relation between entrepreneur intention and entrepreneurial behavior.
\end{abstract}

Keywords - entrepreneurial intention; entrepreneurial behavior; entrepreneurial knowledge; creativity

\section{INTRODUCTION}

Lots of countries pay much more attention to entrepreneurship education. Nowadays Chinese government has also made influential policies to support and encourage the start-up of new business. Entrepreneurship education is especially important in colleges, because the creativity contained in entrepreneurship and establishment of new business may help increase job opportunities and solve employment problems, which can promote the development of national and regional economy. The government and schools emphasize much on the entrepreneurship issues, put forward many programs and policies of supporting college students' entrepreneurship, and encourage them to start entrepreneurial activities, but entrepreneurship are filled with high risks, for college students need to prepare the funds, human resources and equipment before their start-up and they will also be faced with different challenges and risks in their real entrepreneurial activities.

There are many researches on the entrepreneur intention of college students. However, we start an innovative research and discuss whether the creativity and entrepreneurial knowledge of female students in higher vocational colleges could have a positive effect on their entrepreneurial behavior.

\section{RESEARCH THEORY\&HYPOTHESIS}

\section{A. Relation between Entrepreneur Intention \& Entrepreneurial Behavior}

The behavior intention has been studied for many years in the history of psychology. For example Ajzen(1986)[1].For more than ten years, entrepreneur intention is still a quite interesting topic of scholars. Krueger(1993)[11] suggested that entrepreneur intention is the core of understanding the entrepreneurship process, for entrepreneurship is a long-term activity. Intension is a kind of psychological condition that directs our attention to certain target so as to obtain some achievement. Bird(1988)[4] suggested that entrepreneur intention means the inner cognitive, preference and behavior tendency of entrepreneurs in their start-up of new business. Namely, it could be predicted through his willingness and efforts when someone would like to take certain actions. In a word, the behavior is always directed by the intention. 
Intention is an ability of predicting individual behavior and organization results. Crant(1996)[6] suggested that entrepreneur intention is related to individual's optimistic character, education and parents' background of entrepreneurship. Besides, entrepreneur intention could also be influenced by attitude,

\section{H1: The entrepreneur intention of female students in higher vocational colleges has a relates positively to their entrepreneurial behavior}

\section{B. Creativity \&Entrepreneurial}

Many researchers suggested that creation is a psychological thinking process. Scholars have different definitions of creativity. From the view of "personality", some scholar suggested that "creativity involves the activities of individual plan and organization." (Guilford,1967)[8] Some scholar made the definition from the view of "progress" and suggested that creativity is a series of thinking progress. (Torrance, 1974)[14] The definition that is acknowledged by most scholars came from Amiable, named that "creativity is a certain combination of individual personality, cognitive and social environment." Creativity is the source and essence of entrepreneurship. In the process, the entrepreneur need have continuous innovation and rushing creativity, so that he may get innovative ideas, seek new opportunities and achieve the success in the end. Entrepreneurship is the value of innovation. To some extent, the value of innovation is to transform potential knowledge, technology and market opportunities into the productive force in reality.

Psychological factors, individual skills and environment. (Fini et al., 2009)[7] Entrepreneurship refers to taking specific actions and meeting the market demands. Since the entrepreneurship is filled with uncertainty, the Entrepreneurs must make a decision and take actions when facing confusion and risks.(McMullen and Shepherd, 2006)[13] Through taking actions, the entrepreneur may use their creativity and influence to change the current situation and start entrepreneurial activities.

McMullen and Shepherd(2006)[13] suggested that behavior is the core of entrepreneurial theory. When external environment changes and new opportunities come into being, the individual will adopt certain entrepreneurial behavior, as he is influenced by past knowledge and tolerance of uncertainty. Intention is the conceptualization of behavior. The more someone intends to take an action, the higher his behavior will have the possibilities to be executed. (Chandra shekaran et al., 2012)[5] For example, when the entrepreneur has strong entrepreneur intention, he will think about the feasibility of entrepreneurship and try to take certain actions, including preparing funds, seeking opportunities and potential customers, connecting social network, and purchasing equipment and workshop building, so as to improve his entrepreneurial behavior.

H2: The creativity of female students in higher vocational colleges has a positive influence on their entrepreneurial behavior
H3: The creativity plays a mediating role in the effect of entrepreneur intention on the entrepreneurial behavior of female students in higher vocational colleges

\section{The moderating role of Entrepreneurial Knowledge}

According to the Theory of Planned Behavior, intention is an important factor of influencing the behavior. (Ajzen, 1991)[2] But due to the limitations of time difference and data collection, researches in the past could just study the factor of influencing entrepreneur intention (Krueger, 1993)[11], which does not facilitate the verification of relation between intention and behavior and influence of the regulating effect. In the process of entrepreneurship, psychological factor, social regulation, labor market, enterprise environment and economic conditions will be faced with obstruction.

Therefore, this research discusses the moderating effect of entrepreneurial knowledge. As for entrepreneurial knowledge, female college students learn the entrepreneurial courses and own the training related to entrepreneurship. They seek new opportunities from their knowledge and then transform those opportunities into their capacity of starting new business. As we all know, knowledge is one critical factor of economic development, apart from tangible capital and labor force. In the Over flow Theory of Entrepreneurial Knowledge; Audretsch (1995)[3] suggested that under the background of knowledge, there will be more individuals of entrepreneur intention and more opportunities of entrepreneurship. Besides, if the new enterprise fails on the basis of new knowledge, there will be another creation of new knowledge, namely that entrepreneurship may produce new learning effect. Harris (1996)[9] suggested that knowledge is the combination of information, background and experience. The background refers to the attitude of people towards things, which can be influenced by social values, religious belief, nature and gender.

In the research, we adopt the above definition of entrepreneurial knowledge, the female college students learn the entrepreneurial courses and own the training related to entrepreneurship. They seek new opportunities from their knowledge and then transform those opportunities into their capacity of starting new business. Through the research, some scholars found that students are very interested in entrepreneurship. But they don't have enough commercial knowledge, nor do they prepare well for bearing the risks, so that they do not have real entrepreneurial behavior. Wiklund and Shepherd (2003)[15] suggested that entrepreneur intention and entrepreneurial behavior are closely related to individual's knowledge. The background and knowledge that entrepreneur has accumulated can be used to predict their entrepreneurial behavior and lower the possibilities of failure. Therefore, the effect of entrepreneurial knowledge on entrepreneur intention and entrepreneurial behavior could be seen from the above. Although lots of entrepreneurs have the intention of entrepreneurship, they do not take actual actions, mainly because of their inadequate entrepreneurial knowledge.

H4: Entrepreneurial knowledge positively moderates the effect of entrepreneur intention on entrepreneurial behavior of female students in higher vocational colleges 


\section{RESEARCH MODEL}

Based on literature research and qualitative investigation and according to the above research hypothesis, the research model of the paper is put forward as follows:

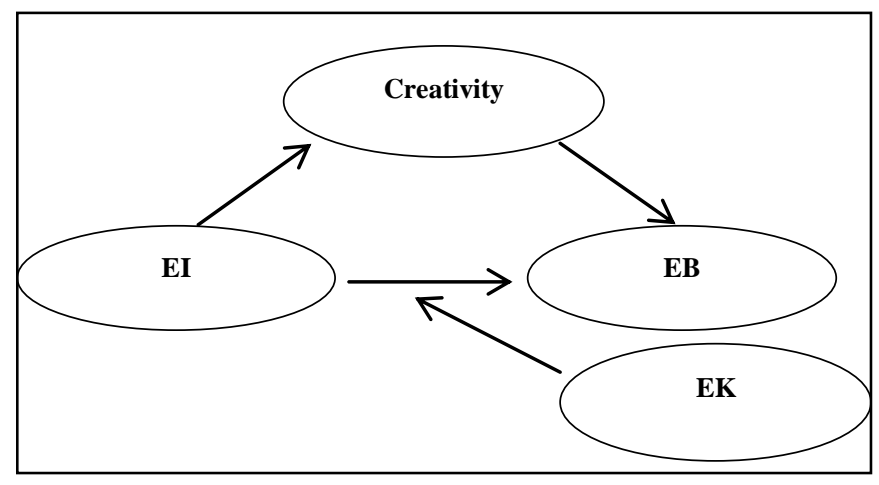

Fig. 1.Hypotheses Relationship

EI: Entrepreneur Intention EB: Entrepreneurial Behavior EK: Entrepreneurial knowledge

\section{CONCLUSION}

In the research, the questionnaire method is adopted to test four variables including entrepreneur intention, creativity, entrepreneurial knowledge and entrepreneurial behavior of female students in higher vocational colleges. The questions in questionnaire use the maturity scale of certain literature for reference, and they are revised depending upon the characteristics of students in higher vocational colleges. In the research, we make an investigation mainly on the female students in higher vocational colleges of Guangdong region. The research is made based on the relation between entrepreneur intention and entrepreneurial behavior of entrepreneurs in the cultural and creative industries. Entrepreneur intention is indeed an important influence on entrepreneurial behavior. Lee(2003)[12] individual's positive attitude towards entrepreneurship education promote the growth of new ventures As for the theoretical significance, the existing findings of different industries can be further developed. Besides, there are few researches on entrepreneur intention and entrepreneurial behavior, mainly because of the difficulty in contacting the research target. Colleges have developed the entrepreneurship education for a long time, but it is difficult to find out the statistics of students' entrepreneurship in the research on the educational achievements. As for the significance of actual practice, knowledge is a very important asset of entrepreneur. Knowledge can make entrepreneurs become much stronger, so that they can have accurate evaluation when facing the uncertainty and risks. Therefore, this study suggests that female students in higher vocational colleges who have the entrepreneur intention shall accumulate more experience related to entrepreneurship, whether job experience, technologies or knowledge. But they shall not fear or give up even if they don't have adequate entrepreneurial knowledge. In addition, the study we shall collect enough sample quantity of statistics to perfect the research. For the further research, the study may compare the difference of students' gender and family background, and analyze the effect of creativity and entrepreneurial knowledge.

\section{References}

[1] Ajzen, Icek, and Thomas J. Madden. "Prediction of Goal-Directed Behavior: Attitudes, Intentions, and Perceived Behavioral Control." Journal of experimental social psychology 22.5 (1986): 453-74.

[2] Ajzen, Icek. "The Theory of Planned Behavior." Organizational behavior and human decision processes 50.2 (1991): 179-211.

[3] Audretsch, David B. "Innovation, Growth and Survival." International journal of industrial organization 13.4 (1995): 441-57.

[4] Bird, Barbara. "Implementing Entrepreneurial Ideas: The Case for Intention." Academy of management Review 13.3 (1988): 442-53.

[5] Chandrashekaran, Rajesh, and Rajneesh Suri. "Effects of Gender and Price Knowledge on Offer Evaluation and Channel Transition in Retail and e-Tail Environments." Journal of Product \& Brand Management 21.3 (2012): 215-25.

[6] Crant, J. Michael. "The Proactive Personality Scale as a Predictor of Entrepreneurial Intentions." (1996).

[7] Fini, Riccardo, et al. "The Foundation of Entrepreneurial Intention." Summer Conference.(2009)

[8] Guilford, JP. "Creativity: Yesterday, Today and Tomorrow." The Journal of Creative Behavior 1.1 (1967): 3-14.

[9] Harris, David B. "Creating a Knowledge Centric Information Technology Environment." (1996).

[10] Hocevar, Dennis. "Ideational Fluency as a Confounding Factor in the Measurement of Originality." Journal of educational psychology 71.2 (1979): 191.

[11] Krueger, Norris F., and Alan L. Carsrud. "Entrepreneurial Intentions: Applying the Theory of Planned Behavior." Entrepreneurship \& Regional Development 5.4 (1993): 315-30.

[12] Lee, Lena, and Poh-Kam Wong. "Attitude Towards Entrepreneurship Education and New Venture Creation." Journal of Enterprising Culture 11.04 (2003): 339-57.

[13] McMullen, Jeffery S., and Dean A. Shepherd. "Entrepreneurial Action and the Role of Uncertainty in the Theory of the Entrepreneur." Academy of Management review 31.1 (2006): 132-52.

[14] Torrance, J. Kenneth. "A Laboratory Investigation of the Effect of Leaching on the Compressibility and Shear Strength of Norwegian Maring Clays." Norwegian Geotechnical Institute Publication.104 (1974).

[15] Wiklund, Johan, and Dean Shepherd. "Research Notes and Commentaries: Knowledge-Based Resources, Entrepreneurial Orientation, and the Performance of Small and Medium-Sized Businesses." Strategic Management Journal 24.13 (2003): 1307-14. 